\title{
Changes In The Regional Responsiveness To Federal Reserve Policy Shocks And The Declining Importance Of Interest Rate Sensitive Industry Sectors
}

\author{
Todd Potts, Indiana University of Pennsylvania
}

David Yerger, (Yerger@iup.edu), Indiana University of Pennsylvania

\begin{abstract}
This paper extends the existing research on regional economic responses to federal-reserve policy shocks along two dimensions. First, we focus on the evolution over time of a particular region's responsiveness to federal funds shocks. This differs from prior work that analyzed differences across regions in their responsiveness to a federal funds shock over a single sample period. For the state of Delaware, we track how the declining importance of manufacturing and construction alters the region's income response to both federal funds rate and oil price shocks. Delaware was selected for analysis because of the large decline since the 1970's in the share of its Gross State Product coming from construction and manufacturing.
\end{abstract}

This paper's second extension of the literature is its use of sequential updating of the data set. Prior research utilized quarterly data sets starting in the late 1950's and ending in the early 1990's. We construct a parsimonious structural VAR model and first estimate the model over the 1958Q1 to 1992 Q4 period. Over this period our results are consistent with earlier findings. Next, we roll the sample period forward one year at a time, keeping the time period's length constant, up through 2004 Q2 and re-estimate the model after each resetting of the sample period.

Overall, our findings are consistent with the view that declines in the importance of interest rate sensitive sectors will lead to declines in the responsiveness of a region's income growth to federal funds rate shocks, but the magnitude of the observed decline in income sensitivity is considerably smaller than what one would forecast based upon the earlier cross-sectional based research. The impact of oil price shocks, however, was contrary to 'conventional wisdom' expectations. Despite the declining share of manufacturing in GSP for Delaware over the rolling sample periods, there was a modest increase in the sensitivity of Delaware real personal income to oil price shocks as the sample period rolled forward.

\section{INTRODUCTION}

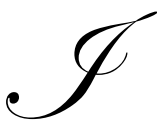

t has been established for some time that U.S. regions historically have differed in their responsiveness to changes in federal-reserve policy as manifested in variations in the federal funds rate. Three potential channels by which regional variation can arise have been identified. These channels involve differences across regions in: the percent of regional output coming from interest-rate sensitive sectors, the percent of regional output coming from small rather than large firms, and the percent of regional lending activity done by small rather than large banks. Empirically, however, for U.S. regions it is only variations in the percent of regional output from interest rate-sensitive sectors that has been shown to correlate significantly, and in the expected manner, with variations in regional income sensitivity to federal-reserve policy shocks. 
Prior studies investigating variation across U.S. regions in income sensitivity to federal-reserve policy shocks utilize data beginning in the latter 1950's and ending no more recently than 1992. Since 1992, the ongoing evolution of the U.S. economy has resulted both in further declines in the relative importance of construction and manufacturing, as measured by percentage of total output, and in considerable variation across U.S. states in their rate of decline in the importance of these two sectors. In this paper, we investigate how the declining importance of construction and manufacturing in total output since 1992 has altered the responsiveness of one region's income to federal funds shocks, the state of Delaware, as compared against the rest of the nation. Our modeling approach also controls for the impact of oil price shocks and allows us to examine the changes over time in the sensitivity of both Delaware and rest-of-nation real personal income to oil price shocks.

Our results indicate one should be cautious in using the previous cross-sectional based research results linking a region's responsiveness to federal funds shocks to its economic structure to infer likely changes over time within a region in its responsiveness to federal funds shocks given changes in the region's economic structure. The summative nature of the cross-sectional regressions across states can mask considerable variation across states in the evolution, if any, in a state's responsiveness to federal funds shocks. We show that regional analysts interested in the impact of federal-reserve policy upon any one particular state or region can gain useful insights by tracing changes over time in the region's responsiveness to federal funds shocks.

Our 'rolling regressions' approach also reveals that one should be cautious in assuming constant parameters in their regression analysis if the entire sample of available data since the latter 1950's is used. When we compare estimation results over the entire sample period against results from our most recent sample period, we find material differences in the estimated impact of both federal funds shocks and oil price shocks upon both rest-of-nation and Delaware real personal income growth. The large structural changes in the U.S. economy at both the national and regional levels over the past 25 years limits the usefulness of data pre 1970 data in forecasting the responsiveness today of national or regional economies to interest rate and oil price shocks.

\section{LITERATURE REVIEW ${ }^{1}$}

During the manufacturing boom years of the post-WWII U.S. economy, material variation existed across regions in their responsiveness to monetary policy. Regions for which manufacturing was more (less) important showed more (less) sensitive to monetary policy shocks in several early studies. Toal (1977) examined regional responses to monetary policy shocks from 1952-1975. He found relatively large regional responses for the Great Lakes, Mideast, and Southeast regions, but small responses in the Rocky Mountain and Southeast regions. Similarly, Garrison and Chang (1979) analyze regional manufacturing earnings from 1969-76 and conclude that monetary policy had the largest impact in the Great Lakes region and the smallest in the Rocky Mountain region. Garrison and Kort (1983) investigate the impact of monetary policy at the state level, rather than using multi-state regions, from 19601978. Consistent with the earlier work, they found that states in the Great Lakes region are the most sensitive to monetary shocks while states in the Rocky Mountains are the least sensitive.

These early studies utilized single-equation models of personal income, earnings, or employment as a function of national money supply (or other monetary policy variable) and other control variables. A potentially important shortcoming of this approach is the lack of accounting for potential feedback effects between the regional economy and the rest of the nation, as well as any feedback effects in the response of monetary policy itself to changes in oil price shocks or other control variables. Carlino and DeFina (1998) controlled for potentially important feedback effects by estimating a VAR model allowing for feedback effects across regions as well as between the monetary policy variable and oil price shocks. This important methodological advance generated regional results consistent with the earlier studies.

Analyzing the 1958-1992 period using quarterly data, they identified five core regions whose responsiveness to monetary policy closely resembled the national response: New England, Mideast, Plains, Southeast, and Far West. Three non-core regions, however, differed significantly from the national response to monetary policy. The Great Lakes region was more responsive to monetary policy shocks than were the core regions while the Rocky Mountains and Southwest regions were less responsive. Over their sample period national manufacturing averaged 19.2\% of 
output while it was $27.0 \%$ of GSP in the Great Lakes region, the highest of all regions, and only $12.6 \%$ and $15.2 \%$ for the Rocky Mountains and Southwest respectfully, the two lowest regional shares.

In an extension of their first paper, Carlino and DeFina (1999) examine the variation in regional responsiveness to monetary policy shocks at the U.S. state level over the same 1958-1992 period. They find substantial variation across states in the eight-quarter cumulative response of real personal income to a one-percentage point federal funds rate increase. Once more, Great Lakes region states are the most sensitive, lead by Michigan's nation-leading $2.7 \%$ point drop in real personal income in response to a $1.0 \%$ point rise in the federal funds rate while the Rocky Mountain and Southwest regions contain most of the states with sensitivities well below the averageacross-all-regions response of a $1.16 \%$ point decline in real personal income per $1.0 \%$ point rise in the federal funds rate.

Carlino and DeFina (1999) also estimate a cross-section regression using the 48 states' cumulative response to a federal funds rate shock as the dependent variable. The explanatory variables include the percentage share of a state's GSP from manufacturing along with other variables meant to proxy alternative explanations of the variation across regions in monetary policy sensitivity. Specifications excluding BEA regional dummy variables find that every $1 \%$ point increase in manufacturing's share of GSP is associated with a $0.027 \%$ to $0.029 \%$ point increase (absolute value sense) in the cumulative response of state real personal income to a $1 \%$ point rise in the federal funds rate. Adding BEA regional dummies lowers the impact to a $0.012 \%$ to $0.015 \%$ point increase in the cumulative state real personal income response to the rise in the federal funds rate. Since the average cumulative response to the federal funds shock was $1.16 \%$ points, this implies that those states most manufacturing dependent over the sample period had sensitivities to federal funds shocks that were 10 to $25 \%$ larger than the national average. ${ }^{2}$

None of the other potential explanations of the variation across regions in their monetary policy sensitivity were well supported by Carlino and DeFina's (1999) cross-section regression results. The percent of small firms in a region had no discernable impact upon the region's sensitivity to federal funds shocks. ${ }^{3}$ The percent of loans by small banks in the region had a negative effect which is the opposite of the sign implied by theory. ${ }^{4}$ Several studies since the work by Carlino and DeFina have reinforced the existence of a linkage between a region's income sensitivity to monetary policy shocks and the share of regional output from interest-sensitive sectors.

Gaudreault (2001) analyzes provincial responses to changes in Canadian monetary conditions. Ontario's output is the most sensitive to changing monetary conditions, followed by Quebec, while the Atlantic and Western provinces lag well behind the national level sensitivity to changing monetary conditions. These findings match up with the relative importance of manufacturing across the provincial economies. Arnold (2001) analyzes the effects of monetary policy across 58 regions within the five largest EU nations and finds that regional sensitivity to monetary policy is related to industry mix in the same manner as previously established for the U.S.A. Arnold and Vrugt (2002) analyze regional data for the Netherlands from 1973 to 1993 across 12 regions and 13 industry sectors. They conclude that industry sector variation accounts for most of the variation in interest sensitivity across regions. Arnold and Vrugt (2004) estimate the impact of interest rate shocks on regional output in Germany across ten provinces over the period 1970-2000. As for Carlino and DeFina (1999), they find that the differential effects of monetary policy are related to variations across provinces in industrial composition, but not to either variations in firm size mix or variations in bank size mix.

\section{MOTIVATION FOR STUDY}

The existing literature clearly has established that variations across regions within a monetary union in their responsiveness to monetary policy shocks is determined in part by the relative importance of interest rate sensitive sectors across regions. Regional policy makers and business decision makers, however, are likely to have different questions regarding the impact of monetary policy upon the regional economy. Is the region presently more, or less, susceptible to monetary policy shocks than the nation as a whole? If so, how large is this difference between the national and regional responses to monetary shocks? Has the region's sensitivity to monetary shocks been changing in recent years, and if so, how? 
We show that insights into these questions can be obtained from the results of a parsimonious structural VAR model that is re-estimated on an annual basis after rolling forward the sample period one year while holding the sample period length constant. This approach helps to minimize the impact from pre 1980 data for which the region was likely to have had a much larger share of its economic activity coming from interest-sensitive sectors. By comparing the estimated impact from monetary policy shocks from the early estimating periods with those of the most recent estimating periods, the stability of the region's sensitivity to monetary shocks can be assessed. If these estimates differ materially across sample periods, then one should utilize the more recent sample period estimates for planning purposes and be cautious about using inferences based on econometric models utilizing all available data since the 1950's.

Our region of analysis in this paper is the state of Delaware. As seen in Figure 1, Delaware has experienced a large decline since 1977 in the relative importance of the interest-sensitive sectors construction and manufacturing. In 1977, Delaware's share of GSP from construction and manufacturing was $40.2 \%$, behind only Michigan and Indiana, and well above the national average of $27.8 \%$. From the early 1980's to the mid 1990's, Delaware's share of GSP from these two sectors fell at a much faster rate than for the entire nation. By 1997, Delaware's share from these sectors had fallen below the national average as it was $20.7 \%$ versus $21.3 \%$ for the entire nation. The once-off shift in Delaware's shares seen in 1998 is due primarily to changing from SIC to NAIC based industrial definitions and should not be interpreted as a sudden large shift in the state's actual economic structure.

Figure 1:\%Share GSP from Construction \& Manuf.

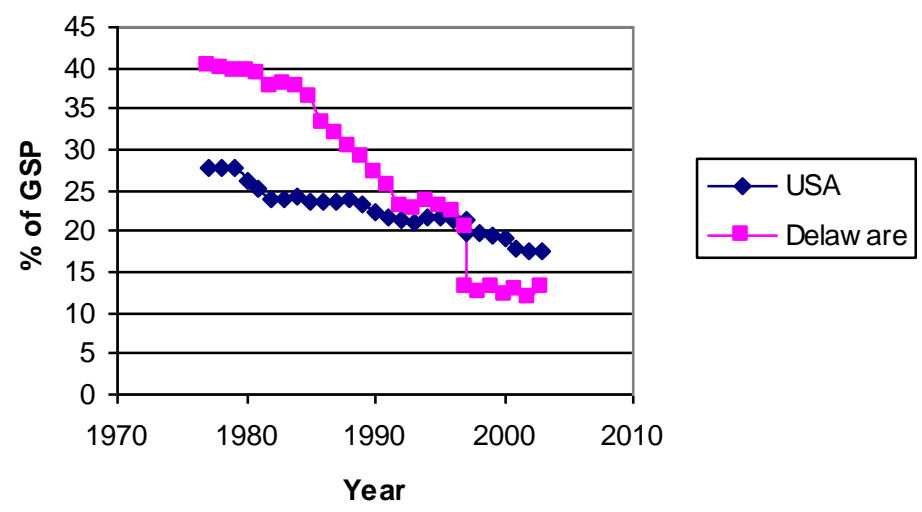

We investigate how Delaware's responsiveness to monetary shocks and oil price shocks has changed since the early 1990's given the underlying changes in its economic structure, and compare Delaware's evolving sensitivity to monetary shocks with the rest-of-nation's responsiveness to monetary and oil price shocks. If any state within the U.S.A. has experienced a material decline in its sensitivity to monetary shocks, Delaware should be that state given the precipitous decline in the share of its output from interest-sensitive sectors.

\section{MODEL}

\section{Model Specification}

Economic activity in the state of Delaware and the rest-of-nation is modeled using a structural vector autoregression (SVAR) model. We analyze the dynamic behavior of the 4 x 1 covariance-stationary vector:

$$
\mathrm{Z}_{\mathrm{t}}=\left[\Delta \mathrm{y}_{\mathrm{st}}, \Delta \mathrm{y}_{\mathrm{Nt}}, \Delta \mathrm{p}_{\mathrm{t}}, \Delta \mathrm{m}_{\mathrm{t}}\right]
$$

where $\Delta y_{s t}$ is the growth rate of state real personal income for Delaware at time t, $\Delta y_{N t}$ is the growth rate of real personal income for the rest-of-nation at time $\mathrm{t}, \Delta \mathrm{p}_{\mathrm{t}}$ is the growth rate of the relative price of oil, and $\Delta \mathrm{m}_{\mathrm{t}}$ a measure of monetary policy actions. 
The dynamics of $Z_{t}$ are represented by

$$
A Z_{t}=B(L) Z_{t-1}+e_{t}
$$

where $\mathrm{A}$ is a $4 \times 4$ matrix of contemporaneous correlation coefficients among the variables, $\mathrm{B}(\mathrm{L})$ is a $4 \times 4$ matrix of polynomials in the lag operator $L$, and $e_{t}$ is $4 \times 1$ vector of structural disturbances, or primitive shocks, so $e_{t}=\left[\varepsilon_{s t}, \varepsilon_{N t}\right.$, $\left.\varepsilon_{\mathrm{pt}}, \varepsilon_{\mathrm{mt}}\right]$. Each variable in the model can be impacted by its own idiosyncratic shock as well as by shocks to any of the other variables. The contemporaneous correlation coefficients in $A$, and the lag operators in $B(L)$ will specify how shocks to any one variable are transmitted throughout the system of equations. If we rewrite equation (2) in its reduced form we see that:

$$
\mathrm{Z}_{\mathrm{t}}=\mathrm{C}(\mathrm{L}) \mathrm{Z}_{\mathrm{t}-1}+\mu_{\mathrm{t}}
$$

where $C(L)=A^{-1} B(L)$ is an infinite-order lag polynomial and $\mu_{t}=A^{-1} e_{t}$ provides the link between the model's structural residuals and its reduced form residuals.

We estimate the elements of A and B(L) using Bernanke's (1986) procedure. First, OLS estimates of the reduced form error terms $\mu_{t}=A^{-1} e_{t}$ are obtained from the estimation of equation (3). Next, the variance-covariance matrix for the structural errors $e_{t}$ are restricted to be both orthogonal, zero contemporaneous covariance, and normalized to unity. This restricts the structural errors variance-covariance matrix to be an identity matrix. Lastly, we need to impose sufficient restrictions upon the A matrix to permit identification of A. Once A is identified, B(L) is estimated from $C(L)=A^{-1} B(L)$ where $C(L)$ comes from the estimation of equation (3).

We place the following restrictions on the A matrix. Shocks to rest-of-nation real personal income do not impact Delaware state real personal income contemporaneously and Delaware state real personal income shocks do not impact rest-of-nation real personal income contemporaneously. Shocks to either region, however, can impact the other region with a lag of at least one quarter. Another restriction is that federal-reserve policy shocks do not contemporaneously affect any of the other variables in the system, but can affect them with a lag of at least one quarter. We also restrict the impact of real oil price shocks upon either Delaware or rest-of-nation real personal income to have zero contemporaneous impact, but allow for impacts with a lag of one quarter or more. The final restriction is that neither Delaware nor rest-of-nation real personal income can contemporaneously affect real oil prices, but can affect them with a lag of at least one quarter. The federal funds rate variable can be impacted contemporaneously, however, by shocks from any of the other variables in the system. With these restrictions in place, the elements of the model are identified.

\section{Selection Of Variables}

The data in this study is quarterly and ranges from 1958 Q1 through 2003 Q4. Delaware State and rest-ofnation economic activity, the $\Delta \mathrm{y}_{\mathrm{s}}$ and $\Delta \mathrm{y}_{\mathrm{N}}$ variables, are measured using real personal income. This is computed using data from BEA on nominal real personal income by state and nation and then deflating using the national CPI. Statelevel CPI are not available over the entire sample period so the national series must be used. Instead of personal income, employment growth could be used as an alternative measure of economic activity. Carlino and DeFina $(1998,1999)$ show that the conclusions drawn regarding differences between a region's responsiveness to monetary shocks and the national average responsiveness to such shocks does not depend upon whether income or employment is used to measure economic activity. Consequently, we confine our analysis to the use of real personal income and focus upon analyzing how the relationships change over time.

The real oil price variable, $\Delta \mathrm{p}$, is included to account for potential aggregate supply shocks and it is computed as the PPI for fuels and related products divided by the total PPI. The monetary policy action variable, $\Delta \mathrm{m}$, is taken as the change in the federal funds rate as is used by Bernanke and Blinder (1992), among others, and is argued by Leeper, Sims, and Zha (1996) to be the preferred measure. Other alternative measures of federal-reserve policy would include changes in non borrowed reserves and the Boschen and Mills (1995) narrative indicator of monetary policy. Once more, however, Carlino and DeFina $(1998,1999)$ show that the analysis of differences between regional 
and national responsiveness to monetary shocks is robust across these three variables capturing federal-reserve policy actions. Hence, we restrict our analysis to using the more frequently utilized federal funds rate measure of federalreserve policy actions.

\section{Specification Issues}

For inferences from this analysis to be valid, the variables in the SVAR need to be stationary. Results from standard Augmented Dickey-Fuller (ADF) unit-root tests are reported in Table 1. The real personal income and real price of oil data is reported in logs and log first-differences (growth rates) while the federal funds rate is in levels and first differences. Not surprisingly, the variables are non stationary in their level or log-level form, but are stationary when converted into first difference growth rates. So, the estimated SVAR model will use stationary first differences of real personal income for Delaware and rest-of-U.S., real personal income, real oil prices, and the federal funds rate.

For the actual estimation of the model, a four-lag structure was used on all variables. This is a sufficiently lengthy period to permit dynamics to work through the system. In addition, the Ljung-Box Q test statistics for the four-lag specification show that the null hypothesis of white noise error terms cannot be rejected at the ??? significance level for any of the system's equations.

Table 1: Augmented Dickey-Fuller Unit-Root Test Results

\begin{tabular}{|c|c|c|}
\hline & Levels & $\underline{1}^{\text {st }}$-Difference \\
\hline Delaware RPI & -2.32 & $-5.71^{*}$ \\
\hline Rest-of-Nation RPI & -2.20 & $-5.27 *$ \\
\hline Relative Price Oil & -0.99 & $-5.38 *$ \\
\hline Fed Funds Rate & -2.06 & $-6.73 *$ \\
\hline
\end{tabular}

*significant at the $1 \%$ level, critical values in Fuller (1976); RPI

is real personal income

\section{EMPIRICAL RESULTS}

We first estimate the model over the 1958 Q1 to 1992 Q4 sample period in order to match exactly the time period used by Carlino and Defina $(1998,1999)$. The cumulative impulse response functions for the impact of a onestandard deviation shock to the federal funds rate upon Delaware real personal income growth (RPI DE) and rest-ofnation real personal income growth are given in Figure 2. Somewhat surprisingly, we see that there is not much difference in the responses to the federal funds shocks despite Delaware's much larger share of GSP from construction and manufacturing over this period than for the rest-of-nation. In fact, Delaware's maximum RPI growth rate response to the shock is -.008225 , only $3.1 \%$ larger than the rest-of-nation's maximum response of -.007977 (tables of these values by quarter not reported to save space).

This quite modest differential is at odds with the realization that Delaware's share of GSP from construction $\&$ manufacturing was approximately $10 \%$ points higher than rest-of-nation over this period as seen in Figure 1.We thus see immediately that one must be cautious in presuming that prior studies' cross-sectional analysis linking income responses to federal funds shocks can be used to infer how any one particular region's responsiveness differs from rest-of-nation. The impulse response functions showing the impact of one-standard deviation real oil price shocks upon Delaware and rest-of-nation real personal income growth are more consistent with Delaware's larger manufacturing share over this period. As seen in Figure 3, Delaware is appreciably more sensitive to oil price shocks over this period than is the rest-of-nation. The maximum RPI growth rate response to the oil price shock is -.002525 for Delaware which is $47.7 \%$ larger than the maximum RPI growth rate response for the rest-of-nation at -.001709 . 
Figure 2: Real Personal Income Growth Response to Federal Funds Shock - 58:1-92:4
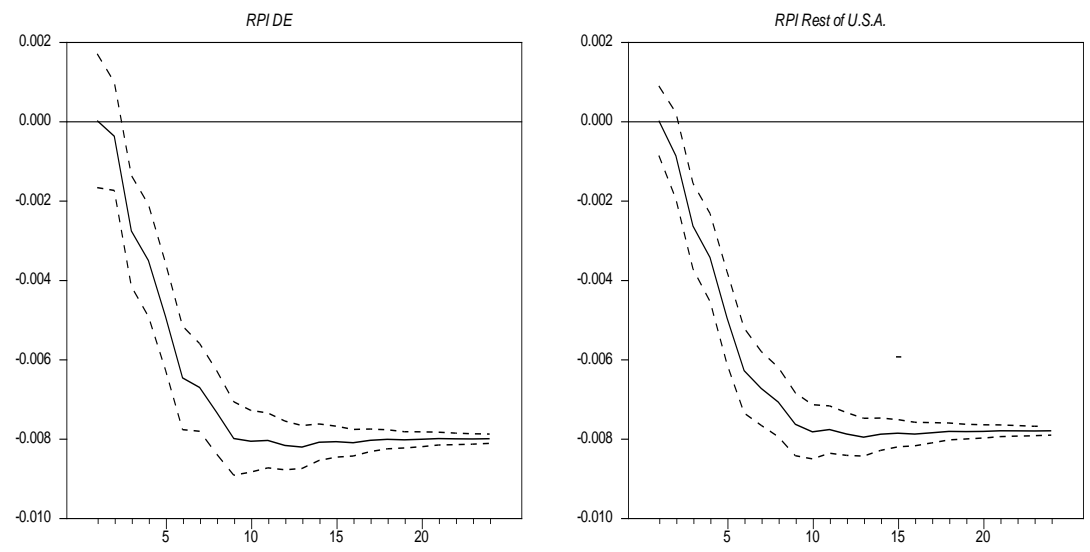

Figure 3: Real Personal Income Growth Response to Real Oil Price Shock - 58:1-92:4
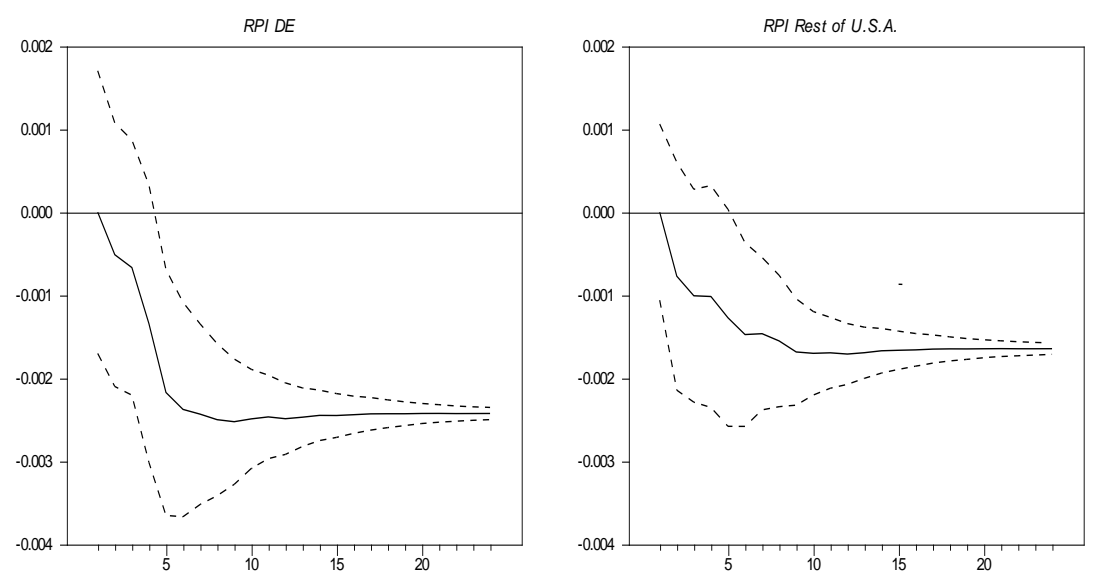

To investigate how these relationships may have changed over time, we next rolled the sample forward to cover 1969 Q1 to 2003 Q4. This time period uses the most recently available data at the time of analysis, and keeps the overall sample period length the same as for the 1958 Q1 to 1992 Q4 period. Over this ending sample period, Delaware's share of GSP from construction and manufacturing converges to the rest-of-nation values by declining much more rapidly than the declines experienced by the rest-of-nation. The question becomes: did Delaware's rapidly declining share of output from construction and manufacturing translate into less of an impact upon RPI growth from a federal funds rate shock, and if so is the decline in responsiveness consistent with the magnitude of the declining importance of interest sensitive sectors? A related question is if Delaware's convergence towards the rest-of-nation in output share from interest sensitive sectors means that Delaware's RPI growth response to federal funds shocks has converged toward rest-of-nation values?

In Figure 4 we see the impulse response functions for RPI growth Delaware and RPI growth rest-of-nation in response to a one-standard deviation shock to the federal funds rate. For Delaware, the maximum response to the federal funds shock is -.006795 while for rest-of-nation the maximum response is -.006543 . So, we find that Delaware's sensitivity to a federal funds shock over this period is 3.9\% larger than for the rest-of-nation (-.006795/.006543). Recall that for the 1958 Q1 to 1992 Q4 period Delaware's estimated sensitivity to a federal funds shock 
was $3.1 \%$ larger than for the rest-of-nation. So, despite going from having a construction and manufacturing share more than $12 \%$ points larger than rest-of-nation to essentially matching these share values for the rest-of-nation, there is no decline in Delaware's RPI growth sensitivity to interest-rate shocks relative to the rest-of-nation's RPI growth sensitivity to interest-rate shocks. In fact, Delaware's sensitivity rises slightly as compared against the rest-of-nation. This result very much is not what one would expect based on the findings from prior work analyzing differences across states in their interest-rate sensitivity.

The absence of a decline in Delaware's sensitivity to a federal funds shock relative to the rest-of-nation's sensitivity to such a shock is because both Delaware and rest-of-nation had very similar declines in their sensitivity to federal funds shocks. For Delaware, the maximum response of RPI growth to federal funds shock fell from -.008225 in the 1958 Q1 to 1992 Q4 period to -.006795 in the 1969 Q1 to 2003 Q4 period, a decline of $17.4 \%$ in the sensitivity of RPI growth. For the rest-of-nation, the maximum response of RPI growth to federal funds shock fell from -.007977 to -.006543 over the same two periods, a decline of $18.0 \%$.

Figure 4: Real Personal Income Growth Response to Federal Funds Shock - 69:1-03:4
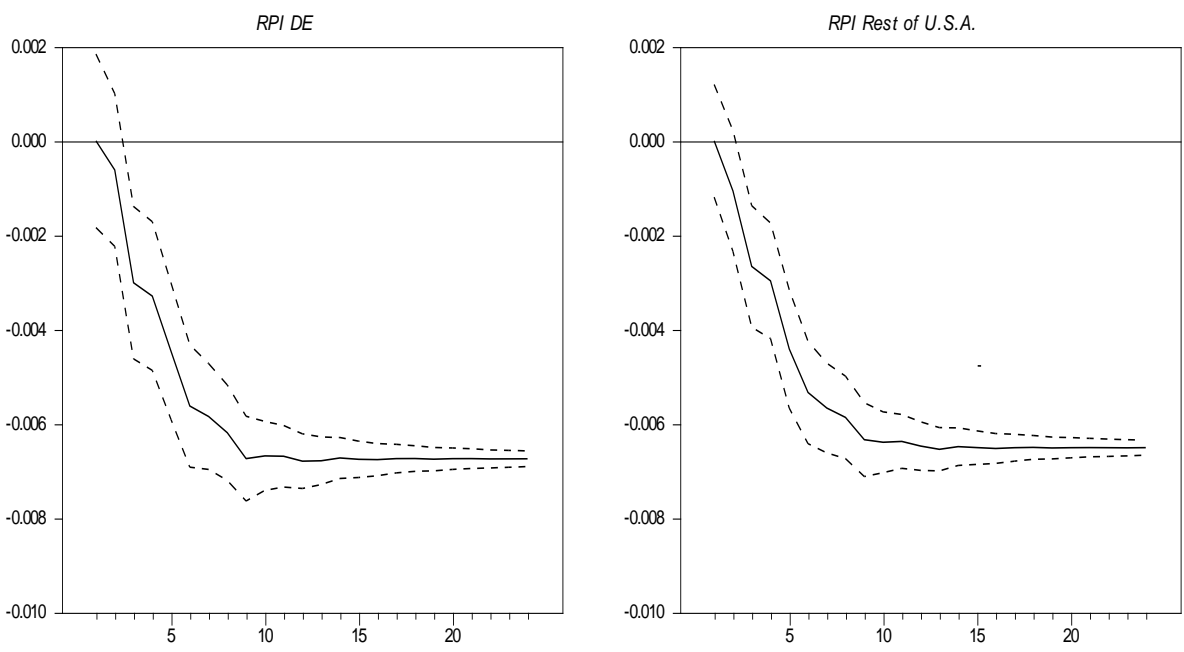

The need to specifically examine the particular region of interest, rather than draw inferences solely from cross-section results, is reinforced further by the analysis of the impact upon RPI growth from real oil price shocks. The impulse response functions for RPI growth Delaware and RPI growth rest-of-nation in response to a one-standard deviation shock to the real oil price is shown in Figure 5. The rest-of-nation impulse response function matches well with the conventional wisdom that the declining importance of oil per $\$ 1,000$ of Real GDP for the national economy means that the economy has become less susceptible to oil price shocks the past 20 years. For the 1969 Q1 to 2003 Q4 time period, the maximum response of RPI rest-of-nation to a real oil price shock is -.001514. This is a decline of $11 \%$ from the estimated maximum response of -.001709 for the 1958 Q1 to 1992 Q4 time period. For Delaware, however, the estimated maximum response of RPI to a real oil price shock in the 1969 Q1 to 2003 Q4 time period is .002681 which is a rise, not a decline, of $6.2 \%$ from the estimated maximum response of -.002525 for the earlier 1958 Q1 to 1992 Q4 period. Despite the large decline in Delaware manufacturing the past 25 years, the state has become slightly more, not appreciably less, sensitive to oil price shocks. Assessing the causes of this result for Delaware are beyond the scope of this paper, but the results do show the value of doing region-specific VAR analysis that allows for changes over time in the estimated relationships. 
Figure 5: Real Personal Income Growth Response to Real Oil Price Shock - 69:1-03:4
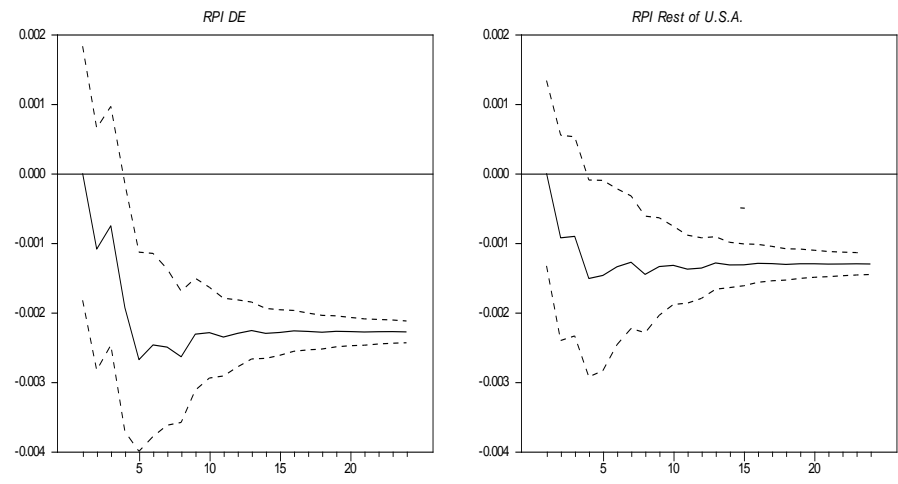

One possible cause of the differences in results over the two sample periods analyzed above is that the estimation results themselves are fragile and that parameter estimates fluctuate somewhat randomly as the sample period is adjusted. We check if the differences in results between the 1958 Q1 to 1992 Q4 sample period and the 1969 Q1 to 2003 Q4 sample period are due to a discernable ongoing trend in the estimated links between RPI growth and federal funds rate or real oil price shocks, or if the results fluctuate randomly from sample period to sample period. To do this, we first run the model over the 1958 Q1 to 1992 Q4 time period and collect the maximum RPI growth rate response to a federal funds shock for both Delaware and rest-of-nation. Next, we rotate the sample period forward one year to 1959 Q1 to 1993 Q4 and repeat the same analysis. This procedure is repeated 12 times until the final time period of 1969 Q1 to 2003 Q4 is estimated. So, in Figures 6 \& 7 Time 1 is 58:1-92:4, Time 2 is 59:1-93:4, ..., and Time 12 is 69:1-03:4.

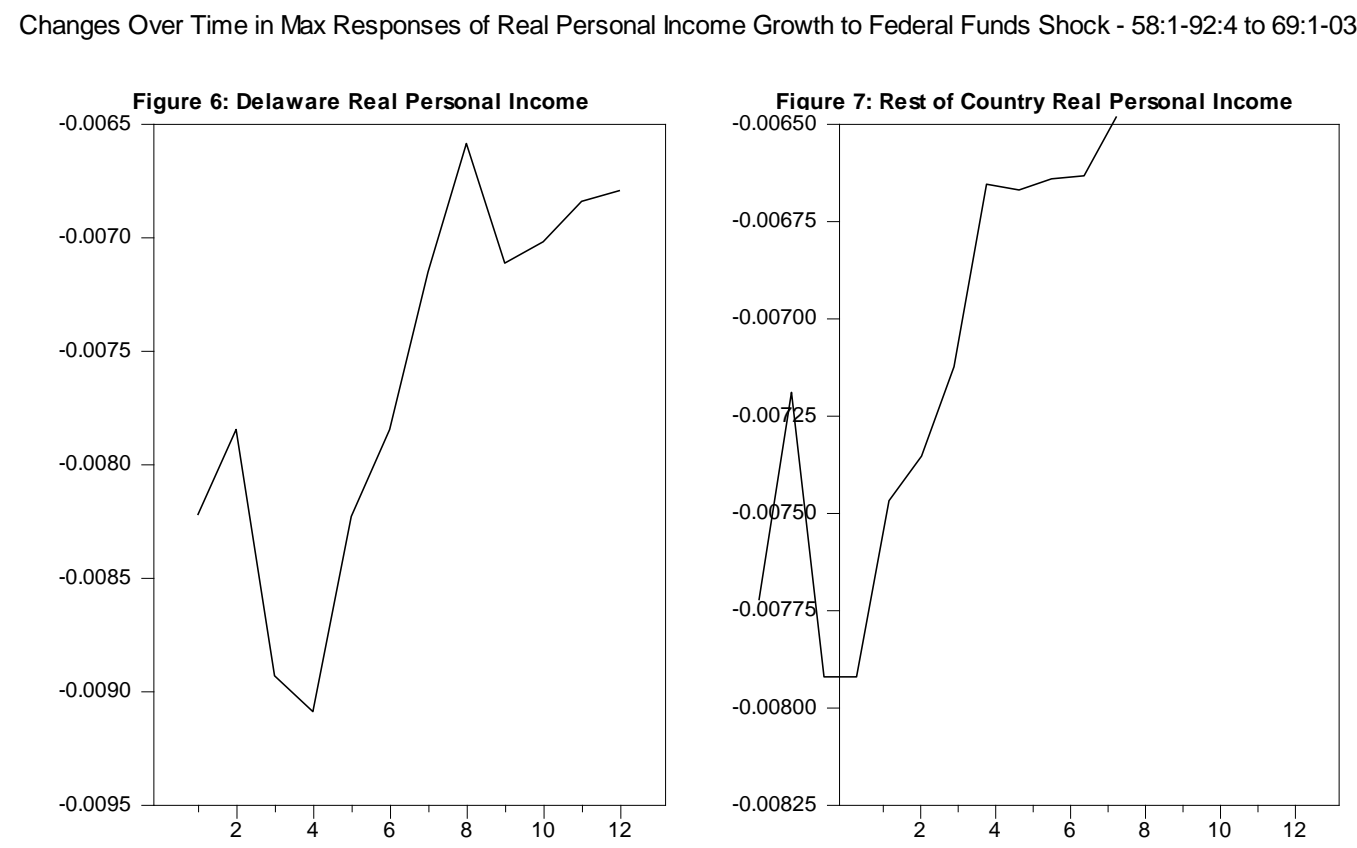

NOTE: Periods 1-12 match samples 58:1-92:4 to 69:1-03:04 respectively 
In Figure 6 the maximum response of Delaware RPI growth to a federal funds shock for each sample period is reported where period 1 is the earliest sample and 12 is the latest sample. While the graph is not monotonic, there is a clear trend over the rolling sample periods for a decline in the sensitivity of Delaware's RPI to federal funds shocks since period 4 (61:4-95:4). The same analysis was done for rest-of-nation and the results are presented in Figure 7. Once more, while not monotonic there is a clear trend in the graph for a decline in the sensitivity of rest-of-nation RPI to federal funds shocks after period 4 . Hence, our earlier findings of $17 \%$ to $18 \%$ reduction over the earliest and latest sample periods in the sensitivity of RPI growth to federal funds shocks for both Delaware and rest-of-nation remains valid. Similarly, our earlier conclusion that Delaware's sensitivity of RPI growth to federal funds shocks has not fallen relative to the rest-of-nation's sensitivity, despite Delaware's much larger drop in its output share from construction and manufacturing, also remains valid.

\section{CONCLUSION}

This study utilizes a structural VAR model to analyze the evolution since the early 1990's in the responsiveness of real personal income (RPI) growth to both federal funds rate shocks and real oil price shocks for both Delaware and the rest-of-nation. We find that there has been a material reduction in the sensitivity of RPI growth to federal funds rate shocks for both Delaware and rest-of-nation. Comparing estimates over the 1958 Q1 to 1992 Q4 period with those from the latest period of 1969 Q1 to 2003 Q4, we find approximately a $17 \%$ to $18 \%$ decline in sensitivity of real personal income growth to federal funds rate shocks for both Delaware and the rest-of-nation.

We completed a rolling regression VAR analysis that rotates the sample period forward one year at a time and shows that the RPI growth responses to federal funds shocks, for both Delaware and rest-of-nation, trended over time in a manner consistent with estimates from the first and last sample periods. These findings call into question the wisdom of estimating regional responses to federal funds shocks using all available data, and constant parameter estimate techniques, if one hopes to use the results to infer how the region's economy may respond in the near future to changes in the federal funds rate.

We find significant differences in the RPI growth responses to real oil price shocks between Delaware and the rest-of-nation. While the rest-of-nation exhibits an $11 \%$ decline it its RPI growth rate sensitivity to real oil price shocks in the 1969 Q1 to 2003 Q4 sample period as compared against the earliest 1958Q1 to 1992 Q4 sample period, for Delaware its RPI growth rate sensitivity to real oil price shocks rises $6.2 \%$ over the two sample periods. These results highlight the importance of having regional analysts examine their region(s) of interest in more exacting detail over time, rather than simply presuming that inferences drawn from national trends or cross-sectional analysis across U.S. regions will yield appropriate insights into their region of interest.

Lastly, our findings do not provide much support for the magnitude of the links estimated in earlier work explaining variations across U.S. states in their sensitivity to federal funds rate shocks as due to variations across states in their share of output from interest sensitive sectors. These cross-section based estimates imply that since Delaware's share of output from interest sensitive sectors fell sharply since 1980, and converged to shares roughly equivalent to rest-of-nation levels, then one should find that Delaware's sensitivity to federal funds shocks fell appreciably more than for the rest-of-nation. Instead, we find that Delaware's sensitivity to federal funds shocks rises slightly relative to rest-of-nation's sensitivity over the past 25 years. At least for the case of Delaware versus rest-ofnation, we cannot explain the evolution of sensitivity to federal funds rate shocks on the basis of the evolving share of output from interest sensitive sectors.

\section{ENDNOTES}

${ }^{1}$ The material in this section is drawn heavily from the excellent, and much more exhaustive, literature reviews found in Carlino and Defina (1998, 1999).

${ }^{2}$ Basis for this estimate is that over their sample period, the average share of GSP from manufacturing was $20.1 \%$ while for several states it exceeded $30 \%$. Using $10 \%$ points as the difference between the manufacturing intensive states and the national average, this adds between $10 * .012=0.12 \%$ points and $10 * .029=0.29 \%$ points to the 
cumulative response of real personal income. Starting from the national average base of $1.16 \%$ points, this is an increase of between $0.12 / 1.16=10.3 \%$ and $0.29 / 1.16=25 \%$

${ }^{3}$ See Bernanke and Blinder (1992) and Gertler and Gilchrist (1994) for an explanation of the 'credit view' of monetary policy transmission in which monetary policy shocks directly impact banks' abilities to make loans. Since small firms are known to be more dependent than large firms upon bank loans for financing, this suggests that regional variation in the small firms versus large firms mix may explain some of the regional variation in sensitivity to monetary shocks. Oliner and Rudebusch (1995) provide another potential 'credit channel' that focuses upon the greater information asymmetry problems between firms and lenders for small firms rather than large firms. This implies that during tighter credit periods, a larger fraction of lending will go to larger firms.

${ }^{4}$ Kashyap and Stein (1995) claim that since larger banks have more funding options for themselves than do smaller banks, then lending by larger banks will be less sensitive to federal-reserve policy changes than will be small bank lending. Hence, an increasing regional share of small banks should make the region more, not less, sensitive to federal funds rate shocks.

\section{REFERENCES}

1. Arnold, Ivo J. M. 2001. The Regional Effects of Monetary Policy in Europe, Journal of Economic Integration, Vol. 16, No. 3, pp. 399-420.

2. Arnold, Ivo J. M. and Evert Vrugt. 2002. Regional Effects of Monetary Policy in the Netherlands, International Journal of Business and Economics, Vol. 1, No. 2, pp. 123-134.

3. Arnold, Ivo J. M. and Evert Vrugt. 2004. Firm Size, Industry Mix, and the Regional Transmission of Monetary Policy in Germany, German Economic Review, Vol. 5, No. 1, pp. 35-55.

4. Bernanke, Ben and Alan Blinder. 1992. The Federal Funds Rate and the Channels of Monetary Transmission, American Economic Review, Vol. 82, pp. 901-921.

5. Boschen, John and Leonard Mills. 1995. The Relation between Narrative and Money Market Indicators of Monetary Policy, Economic Inquiry, Vol. 33, pp. 24-44.

6. Carlino, Gerald and Robert Defina. 1998. The Differential Regional Effects of Monetary Policy, The Review of Economics and Statistics, Vol. 80, pp. 572-587.

7. Carlino, Gerald and Robert Defina. 1999. The Differential Regional Effects of Monetary Policy: Evidence From the U.S. States, Journal of Regional Science, Vol. 39, No. 2, pp. 339-358.

8. $\quad$ Fuller, W. A. 1976. Time Series (New York, Wiley).

9. Garrison, Charles and Hui S. Chang. 1979. The Effects of Monetary Forces in Regional Economic Activity, Journal of Regional Science, Vol. 19, pp. 15-29.

10. Garrison, Charles and John Kort. 1983. Regional Impact of Monetary and Fiscal Policy: A Comment, Journal of Regional Science, Vol. 23, pp. 249-261.

11. Gaudreault, Carl. 2001. Impact economique regional d'un changement dans les conditions monetaires au Canada, Working Paper Ministry of Finance, Government of Canada.

12. Gertler, Mark and Simon Gilchrist. 1994. Monetary Policy, Business Cycles, and the Behavior of Small Manufacturing Firms, Quarterly Journal of Economics, Vol. 109, pp. 309-340.

13. Kashyap, Anil and Jeremy Stein. 1995. The Impact of Monetary Policy on Bank Balance Sheets, Carnegie Rochester Conference Series on Public Policy, Vol. 42, pp. 151-195.

14. Leeper, Eric, Christopher Sims, and Tan Zha. 1996. What Does Monetary Policy Do? Brookings Papers on Economic Activity, Vol. 2, pp. 1-78.

15. Oliner, Stephen and Glenn Rudebusch. 1995. Is There a Bank Lending Channel for Monetary Policy? Federal Reserve Bank of San Francisco Economic Review, pp. 2-21.

16. Toal, William. 1977. Regional Impacts of Monetary and Fiscal Policies in the Postwar Period: Some Initial Tests, Federal Reserve Bank of Atlanta Working Paper. 


\section{NOTES}

